\title{
Evaluating Climate Change: Pro-Poor Perspectives
}

\author{
Merylyn Hedger, Martin Greeley and Jennifer Leavy'
}

\begin{abstract}
1 Evaluation of climate change adaptation and development linkages

Global efforts on adaptation are likely to be significantly scaled up with considerable additional funds from Official Development Assistance (ODA), innovatory finance such as the Adaptation Fund, earmarking of emissions trading auctioning revenues, and increased flows from private foundations. The funding of adaptation and modes of delivery has been a critical area for discussion within the negotiations surrounding the United Nations Framework Convention on Climate Change (UNFCCC) and this will continue within the Bali Action Plan and in the evolution of the post-2012 climate change agreement. As these developments take place, it will be vital to ensure that evaluation is included from the outset so that funds are spent equitably, efficiently and effectively in ways that are sustainable. We need to learn from what we have done so far.
\end{abstract}

There is as yet no agreement about how far the global community will go to stabilise greenhouse gas emissions, or how that might be achieved, and therefore how much adaptation to climate change will ultimately be necessary. Because of the causes of climate change, the key drivers for action and resources are likely to be resolved with reference to the international context, principally the UNFCCC. However, adaptation is delivered within local contexts and matters ultimately at the household level, particularly from the perspective of poverty alleviation. There is therefore a need to develop integrated frameworks for the evaluation of climate change adaptation interventions (CCAls) from international, through national to community level.

This new interest in the evaluation of climate change can add reflection to ongoing changes within the 'evaluation industry' and also to support some broad innovations in development finance, which is already interacting with climate change adaptation funding. With increasing volumes of international development assistance a more coherent approach has been stimulated to deliver the UN Millennium Development Goals (MDGs). There is also a new momentum to integrate global funding mechanisms with mainstream support to national agendas. There is a greater interest in ensuring country-led poverty reduction processes become the focus of evaluation effort and greater engagement in developing country partners. Following high-level meetings, the Paris Declaration was agreed (2005) with a set of principles to improve the harmonisation of development assistance and alignment with national development objectives. These have been adopted by the leading aid agencies which has led to increased concerns about the quality of the evidence base on what works and what does not. With commitment to development goals in the form of the MDGs and other internationally agreed development targets, there is now renewed pressure to improve the rigour of evaluation and to incorporate lessons effectively. Accompanying this trend is a move to larger scale, sector-wide thematic country level and synthesis evaluations.

At the same time, the development of new aid instruments - notably investing in Poverty Reduction Strategy Papers (PRSPs) through direct budget support - has opened fresh challenges in assessing aid impact. In many ways, the changing context and trends in evaluation in international development can support and integrate the needs for CCAl evaluation. Evaluation is increasingly being recognised as a critical need, which requires stronger collective commitment and the use of innovative institutional partnership arrangements to share the burden of 
providing rigorous evaluative evidence of significant common interest.

However, analyses of the National Adaptation Programmes of Action (NAPAs) by the least developed countries (LDCs), associated with the UNFCCC, have shown the challenges of integrating climate change into PRSPs (McGray et al. 2007: 34). Mainstreaming adaptation into development agendas has not yet penetrated the world of PRSPs, and there has been a general disconnection between NAPAs and PRSPs. UNFCCC workshops have identified that crucially little work has been undertaken to integrate adaptation into development plans or within existing poverty alleviation agendas (UNFCCC 2007). Therefore, moves to streamline development aid and deliver it straight into national budgets could mean that aims to account for CCAI for the poor and vulnerable may actually be more difficult to achieve and be regarded as new conditionalities. Concerns have already been expressed within the UNFCCC process that funds for climate change are new and additional to existing aid.

OECD's Development Assistance Committee agreed a standard set of international criteria to guide all evaluations of development assistance in 1991 which are widely used. These are: relevance, effectiveness, efficiency, impact and sustainability. ${ }^{1}$ However, in view of the causes and outcomes of climate change, it is crucial to include equity as a fundamental criterion. Adaptation aims to reduce vulnerability to climate change shocks and stresses. However, vulnerability also depends on socioeconomic factors, which implies that any given adaptation may reduce vulnerability inconsistently across groups. Adaptation can reinforce existing inequalities, or it could be designed in such a way as to protect especially vulnerable groups. Adaptation interventions that are inequitable may well undermine the potential for welfare gains in the future, and are unsustainable.

Frameworks for evaluating the success of climate change adaptation must recognise that CCAls occur at all scales, forcing reflection on what constitutes success at each level. Each of the following scales is relevant for developing adaptation evaluations:

- globally and system-wide (e.g. effectiveness of global markets for risk transfer; adaptation in global commodity markets)
- global finance delivery mechanisms (e.g effectiveness of the Global Environment Facility (GEF) adaptation funds or the Adaptation Fund in promoting adaptation)

- national scales (e.g. efficacy of legislative and institutional arrangements)

- across adaptation policies and programmes (e.g. implementation framework for NAPAs or programme-wide mechanisms like the Department for International Development (DFID)/International Development Research Centre (IDRC) Climate Change Adaptation in Africa programme)

- at the community-based project level (e.g. effectiveness of adaptation interventions on household vulnerability reduction).

\section{Current status on the evaluation of climate change adaptation interventions}

CCAls are subject to intense theoretical debates about how to define adaptation and whether adaptation is just about the enhancement of adaptive capacity. ${ }^{2}$ There is a need to be able to evaluate adaptation to climate change and also measures which increase resilience to current climate variability within a broader development perspective. This can mean that climate change provides a longer-term perspective for development efforts, which opens up the possibility of new and different strategies.

Analysis by the World Resources Institute (WRI) has shown that 'discrete' adaptation, where implementers and funders have climate change specifically in mind, is only a part of what is regarded as 'adaptation effort'. It is also possible to identify 'serendipitous' adaptation, where climate change adaptation interventions embrace activities undertaken for development objectives that incidentally may support adaptation; and also the 'climate-proofing' of development effort, where additional activities are added to an ongoing development initiative (McGray et al. 2007: 13). The logic here is that evaluations of the CCAI are likely to be able to work within these different institutional and funding frameworks, and will not necessarily be working in precisely defined situations towards clear goals and objectives set at the outset, which can be measured. Where opportunities arise for integration at critical stages, they should be taken, for example by using climate risk screening processes on development portfolios. 
Very few evaluations of CCAl adaptation have been undertaken, although a comprehensive, multi-scale and multi-sectoral framework on monitoring has been devised by UNDP (2008), and the IDRC has devised a methodology for using monitoring and evaluation as a capacity development tool (IDRC 2008).

All the key tools, methods and approaches, which have been devised for assessing development effectiveness, have a role to play in assessing CCAls, particularly as the (WRI) analysis has shown that the largest numbers of CCAls are at community level, and agriculture, disaster risk management, water resource management and coastal resources predominated. One key area where there is significant experience is on livelihoods evaluation. There exists a wide range of monitoring and evaluation (M\&E) tools used and developed for contexts of sustainable livelihoods and poverty reduction. Livelihoods $M \& E$ is characterised by its focus on three main areas of interest: process, outcomes and impacts. Livelihoods M\&E tools vary in terms of how much weight they lend each of these foci-some concentrate on developing indicators of achievement of material goals or outcomes, others are concerned with processes and (e.g. in the case of outcome mapping) behavioural changes as outcomes. Others still step away from (quantitative) indicators and instead explore qualitatively 'stories' about changes (e.g. 'most significant change' approach).

Examining the few climate change adaptation evaluation documents contained in the GEF database provides an overview of approaches used for evaluating interventions to support adaptation to climate change - whether adaptation objectives and outcomes are stated ex ante or ex post. Most of the completed evaluations of CCAls and current CCAI projects relate to rural livelihoods type projects where there has been a strong reliance on qualitative methods, mainly through interviews focusing on project staff. While many projects are participatory and demand driven, $M \& E$ has been designed post hoc and not embedded in the project, but undertaken independently. There is little indication that baselines are established from the outset against which to measure progress.

To make evaluation of CCAls more robust, several aspects need to be covered. In the M\&E of projects and programmes attribution, including establishing a credible counterfactual to enable comparisons of outcomes with and without the intervention, and addressing evaluation of 'success' in absence of event, are key components. This will also entail clear definitions of vulnerabilities at the local level, as well as establishing baseline scenarios, risk analysis, development of monitoring procedures, and identifying strengths and weaknesses relevant to improving community resilience.

The further key modifications that are needed to evaluate CCAls include:

- Timeframes: mechanisms to provide ongoing feedback on impacts beyond the lifespan of the project and institutional memory - information storage and retrieval systems

- Methods: participatory evaluation - $360^{\circ}$

- Impact indicators: developed in partnership with beneficiaries

- Clear and effective feedback mechanisms: from local through national, regional and international levels, from household to project to programme to policy.

It is known from established evaluation methodology that one of the biggest challenges is timing in approaches to M\&E, especially in the context of unpredictable events including the identification of indicators that can be monitored over time to understand changing risk factors, impacts and conditions. Evaluations of slow-onset disasters provide valuable lessons for dealing with longer timescales coupled with the need to respond rapidly to an unpredicted event. One important finding is the tendency to compromise on community participation throughout the programme cycle when there is a need to respond rapidly. In terms of slowonset crises, there is much room for contacting communities earlier and identifying interventions building on community priorities and capacities, making potential adaptation more effective, timely and sustainable. Long timescales should also create better opportunities to build on national strategies for climate change adaptation and to build adaptation into longer-term strategies for food security and poverty alleviation. Institutional memory is key for learning from interventions and more so given the time horizons related to climate change. Given the difficulties in tracking down stakeholders/ beneficiaries even when evaluating projects on relatively short 2-3 year timescales, this is not trivial and calls for strong feedback mechanisms, effective 
gathering and recording of appropriate information, and reliable and accessible information repositories.

Finally, it should be made explicit that current databases of adaptation under-report institutional and programmatic interventions, probably in view of their comparatively early state of progress, compared to other development interventions so these have been under-analysed and evaluated. Climate change negotiators and policy analysts are well aware that these are sensitive and contested areas: the lack of consensus at a global level on adaptation has already been indicated. This deficit is likely to extend downwards to national differences, between ministries, within civil society groups, across programme administration, and across scales. This will further complicate the evaluation of the CCAl. Evaluators however, are well-used to entering controversial territory. To avoid conflict, there is a need to carefully choose methods and indicators and aim for transparency in reporting their use and outcomes. Some methodologies, for example outcome mapping, work in an integrally participatory way.

\section{Pro-poor critical issues for evaluation}

If the ultimate aim of adaptation-focused projects is to help communities and households to reduce their vulnerability to the impacts of climate change, two important questions are:

1 How has adaptation increased the asset portfolio and governance support in such a way that decreases vulnerability to climate change?

2 To what extent has adaptation investment resulted in improvement?

This implies the need for identifying appropriate, wide-ranging indicators, encompassing processes as well as outcomes, so that one can ultimately determine what is happening at the level of the household to reduce vulnerability to climate change risks and impacts. It is also necessary to ensure there are effective mechanisms to feed this data back up through the 'levels', as well as ways to measure/ provide information across these indicators. Most of the evaluations so far undertaken do list programme and project-level context-relevant indicators, as indicated, but there needs to be more systematic engagement with ultimate beneficiaries (households and communities), including $360^{\circ}$ feedback loops as a component of participatory evaluation and stakeholder/beneficiary-determined indicators. Given the potential for differential impacts on men and women in terms of effects of climate change impacts on livelihoods, participation of women and the development of gender-sensitive indicators are also necessary. Again, there are clear benefits to be gained in carrying these all the way through the different levels of engagement - household, local/community, programme, sub-national regions (local government), national, regional, international.

A considerable amount of evaluation of development has taken place on a project level and recent attempts to improve the rigour of impact evaluations have been concerned with identifying a control group, and developing counterfactuals and baselines for project outcomes. Here there is an ethical objection to the household-level randomised experimental design in that we are deliberately not providing an intervention - to the untreated group in order to provide a baseline to assess whether the intervention is any good. With CCAI interventions, this is only partially valid since in practice, we cannot programme to work with everyone facing similar climate change risk at the same time. The real need now is for the climate change adaptation industry to engage with the professionals working in evaluation and develop coherent evaluation strategies that are sensitive to the needs of best practice evaluation. The long-term benefits to CCAI welfare effectiveness may be large.

For CCAls, the core analytical perspective for evaluation is to measure whether household climate change vulnerability has been sustainably reduced. If it is accepted that changes in household welfare affect their resilience to climate change events, especially poor households that are most vulnerable to lasting damage from climate change events, is the 'bottom line' in assessing CCAI impact, then the tools of modern evaluation practice are highly pertinent. Impact assessment design has become a central focus of the aid evaluation industry and has been driven by a concern to reproduce the science of the laboratory in the social world, measuring welfare outcomes at the household-level. Evaluation methods will vary according to the type of CCAl.

- Where CCAls are about reducing the core vulnerability of households: if household capacity to manage climate change events (i.e. their resilience) is measured through household wealth defined by their asset portfolio, as in the sustainable livelihoods 
framework, then before and after comparisons can provide a measure of impact.

- If the CCAI involves building response capacity, for example a disaster preparedness intervention, it may not impact at the level of the household until a climate-related event occurs. This type of disaster risk reduction intervention is in a wider group of interventions that are driven by a precautionary motive. Unless the event occurs, such precautionary interventions have no immediate welfare impact and rely on theory to establish their efficiency and effectiveness. Adaptive capacity interventions - to both rapid and slow onset climate change-related events are the major component of this set.

- CCAls to enhance the management of climate risk are potentially the most complex to evaluate. Such interventions are anyway precautionary, unless our science becomes good enough to make predictions reliable, and involve the use of climate screening guidelines to avoid maladaptation practice. They involve decisions about changing proposed development interventions to incorporate climate risk. They are susceptible to Type One Errors, making changes when no risk is there, in order to prevent Type Two Errors when failure to adapt results in climate change having avoidable negative impact.

- Interventions directly to confront climate change are the most straightforward to evaluate. These are adaptive responses to specific identified climate change events where we are fairly certain of very high risk, and of welfare loss through failure to act. Evaluation here is concerned primarily with the cost-effectiveness of alternative responses, allowing for distributional consequences.

\section{Conclusions}

CCAls are diverse, cutting across sectors and scales (project, programme, national, international, systemic). They need to deliver outcomes down to the household level. They need to enable unknown changes to be tackled over the next decades. CCAls are delivered though a variety of institutional delivery mechanisms. There are known barriers and constraints to their delivery. Efforts should be made to build a consensus about what is successful adaptation, so that there is a clearer framework for evaluation of interventions intended to deliver it.
Evaluation can provide a rigorous and technical methodology to generate independent assessment. $A$ variety of monitoring and evaluation tools could be used to cope with the complexities and the specific context in which the tools are being used. Where CCAls closely match development projects, this is already happening. There is a need for a framework to measure the accumulation and culmination of effort at local, national and global levels. So the key will be to devise indicators which can measure progress in knowledge generation, its assimilation and application and flexible institutions at all scales. Ultimately, successful adaptation will be measured on multidecadal timeframes based on the achievement of development objectives sensitive to a changing climate. However, the assessment of such long-term achievements would require monitoring and evaluation to extend over periods much longer than with those associated with project and programme lifetimes.

While outcomes at household level to increase assets and access to resources will ultimately be dependent on local level specific contexts, resources are likely to be generated for these from the international level and will work within national level legal and institutional frameworks. Rather than fostering an explosion of evaluations of the multiplicity of interventions which can be labelled as CCAI, this calls for greater efforts in ensuring adaptation rests within PRSPs at the outset with consequent integration of NAPAs. In addition, it is vital that sectoral plans, particularly water and agriculture, have climate change fully integrated within them Adaptation evaluations must then be integrated with existing evaluation frameworks to avoid issue fatigue on the ground. Commonly used indicator frameworks for vulnerability and sustainable livelihoods analysis can provide a considerable amount of data that is compatible with climate change adaptation, which require no more than 're-packaging' to fit an adaptation context. Impact analysis has methods for measuring the relevant changes. Evaluators are well-used to entering contested territory and some new opportunities can be faced, such as evaluating the effectiveness of the Adaptation Fund. 


\section{Notes}

* This article has been derived from a longer paper commissioned for the Global Environment Facility (GEF) Conference on Evaluating Climate Change and Development (10-13 May 2008) which

\section{References}

Adger, W.N.; Agrawala, S.; Mirza, M.M.Q.; Conde, C. O'Brien, K.; Pulhin, J.; Pulwarty, R.; Smit, B. and Takahashi, K. (2007) 'Assessment of Adaptation Practices, Options, Constraints and Capacity', in M.L. Parry, O.F. Canziani, J.P. Palutikof, P.J. van der Linden and C.E. Hanson (eds), Climate Change 2007: Impacts, Adaptation and Vulnerability. Contribution of Working Group II to the Fourth Assessment Report of the Intergovernmental Panel on Climate Change, Cambridge: Cambridge University Press, 717-43, www.ipcc.ch/pdf/assessment-report/ ar4/ug2/ar4-wg2-chapter17.pdf (accessed 14 July 2008)

DFID (2005) Guidance on Evaluation and Review for DFID Staff, London: Evaluation Department, DFID, July

Hedger, M.M.; Mitchell, T.; Leavy, J.; Horrocks, L. and Greeley, M. (2008) 'Desk Review of Adaptation to Climate Change from a Development Perspective', Draft Report to Global Environmental Facility, Brighton: IDS, May undertook a desk review of the current 'state of the art' and identified gaps (Hedger et al. 2008). 1 See DFID (2005).

2 Key aspects are covered in Adger et al. (2007).

IDRC (2008) 'CCAA's Approach to Using Monitoring and Evaluation to Strengthen Climate Adaptive Capacity', N. Beaulieu, F. Denton, V. Orindi, S. Carter and S. Anderson paper for the International Workshop on Evaluating Climate Change and Development', Alexandria, 10-13 May McGray, H.; Bradley, R. and Hammill, A. (2007) Weathering the Storm: Options for Framing Adaptation and Development, Washington DC: World Resources Institute, http://pdf.wri.org/ weathering_the_storm.pdf (accessed 14 July 2008)

UNDP (2008) Proposed Framework for Monitoring and Evaluating Adaptation to Climate Change, N. Brooks and J. Frankel Reed paper for the GEF International Workshop on Evaluating Climate Change and Development, Alexandria, 10-13 May UNFCCC (2007) Climate Change: Impacts, Adaptation and Vulnerability in Developing Countries, http://unfccc.int/files/essential_background/ background_publications_htmlpdf/application/txt/ pub_07_impacts.pdf (accessed 14 July 2008) 